\title{
SCAN PLANNING OPTIMIZATION FOR OUTDOOR ARCHAEOLOGICAL SITES
}

\author{
L. Díaz-Vilariño ${ }^{1, *}$, E. Frías ${ }^{1}$, M. Previtali ${ }^{2}$, M. Scaioni ${ }^{2}$, J. Balado $^{1}$ \\ ${ }^{1}$ Applied Geotechnologies Group, Dept. Natural Resources and Environmental Engineering, University of Vigo, Campus Lagoas- \\ Marcosende, CP 36310 Vigo, Spain - (lucia, efrias, jbalado)@uvigo.es \\ ${ }^{2}$ Politecnico di Milano, Department of Architecture, Built Environment and Construction Engineering (DABC), Via Ponzio 31, \\ 20133 Milano, Italy - (mattia.previtali, marco.scaioni)@ polimi.it
}

Commission II, WG II/8

KEY WORDS: HBIM, scan planning, visibility, spatial analysis, computational geometry, archaeology, heritage reconstruction

\begin{abstract}
:
The protection and management of archaeological sites require from a deep documentation and analysis, and although hand measuring and documentation is the cheapest way for collecting data, laser scanner has been gradually integrated for the geometrical data capture since point clouds have a high quality in terms of accuracy, precision and resolution. Although acquisition with laser scanner is considered a quick process, scan planning is of high relevance when considering outdoor archaeological sites because of their large size and complexity. In this paper, an automatic methodology to optimize the number and position of scans in order to obtain a point cloud of high quality in terms of data completeness is proposed. The aim of the methodology is to minimize the number of scans, minimizing at the same time the estimated surveying time and the amount of repetitive acquired data. Scan candidates are generated by using a grid-based and a triangulation-based distribution, and results show a faster analysis when triangulation is implemented. The methodology is tested into two real case studies from Italy and Spain, showing the applicability of scan planning in archaeological sites.
\end{abstract}

\section{INTRODUCTION}

Archaeological sites especially those outdoor sites are vulnerable to changing weather patterns and other environmental hazards, and their protection and management includes a deep characterization and analysis. The full characterization of archaeological sites using conventional techniques is a long process. The traditional hand measuring documenting method is the cheapest way of collecting data. However, this is documenting strategy is generally time consuming, inaccurate, subjective, and having no coordinate reference (Barsanti et al., 2012). For this reason, in the recent years, laser scanner has been proposed for the geometrical data capture since point clouds have a high quality in terms of accuracy, precision and resolution. Laser scanning has already proved their impact and the potential on the excavation (Doneus and Neubauer, 2005) and the post-excavation phase (Forte at al., 2012), increasing the quality of the archaeological documentation and enhancing the understanding of the archaeological sites (Remondino and Campana, 2014). Additionally, 3D laser technology contributes to the production of three-dimensional models (Balletti et al., 2015), animations and illustrations for presentation in virtual museums (Barbieri et al., 2018), as well as on the web. The non-contact nature of laser scanning allows recording excavated surfaces that are too vulnerable to be surveyed by other strategies. For example, laser scanning can be fruitfully used to document fragile mosaics, organic material and other surfaces that can be damaged by contact measurements. In the post-excavation phase laser scanning data can be effectively used for different kind of purposes and may involve different experts. Indeed, an archaeologist might be interested in understanding how one feature in the landscape relates to another. For example, Entwistle et al. (2009) presents an integration strategy between high-resolution 3D site model derived with terrestrial laser scanning and soil chemical data obtained from an abandoned settlement site to make hypothesis on settlement layout and activity. On the other hand, conservators might want to know how quickly feature changes. Kincey et al. (2017) and Previtali et al. (2018) present a strategy for archaeological site erosion monitoring comparing terrestrial laser scans acquired at different epochs.

Since the use of 3D laser scanner in archaeological application many have such a large variety of purposes the specific aim of the survey is fundamental to define acquisition requirements. Measurement accuracy is affected not only by the scanner's typology (e.g., time of flight, phase shift or triangulation based) and specifications, but also the scanning configuration and conditions. For example, scanning geometry, i.e. the relative location and orientation of the TLS with respect to the scanned surface, significantly influence the local incidence angle and consequently not only the local point density of the laser points but also measurement accuracy (Boehler et al., 2003). In many cases, a major concern in the scanning procedure is the quality in terms of data completeness and the cost in terms of time, especially for big archaeological sites. For those reason a good planning of the scan location is of primary importance for a successful survey. The main aim of scan planning is to define the scan positioning in a way that can satisfy the requested level of detail and data coverage. Constraints and task requirements such as full coverage, overlap ratio, point density, and incidence angle are considered in the view planning process. This problem has mainly addressed in the case of indoor scan planning and robot navigation (Fujimoto et al., 2008). The problem of scan optimization was also addressed in more general cases of indoor or outdoor environments. Low (2006) presents a specific metric for plan optimization in the case of indoor environment. Blaer and Allen (2006) present a two-step procedure. In the first step a 2D map is used to plan a set of initial acquisition. Those acquisitions are then used to refine the scan location. Nagatani et al. (2010) focus on outdoor scan planning of large buildings by using a mobile robot. However, none of those methods is specifically designed for acquisition or archaeological sites. Instead, Ahn and Wohn (2016) are addressing the issue of scan planning optimization for cultural heritage recording, mainly buildings. The proposed method is an interactive one and 
integrates some heuristics. The developed tools support the user defining the next best position in a feasible region.

This paper proposes the implementation of a methodology to optimize the number and position of scans in order to obtain a point cloud of high quality in terms of data completeness and density, and thus, optimizing surveying time.

The rest of the paper is structured as follows. Section 2 presents the methodology implemented. The results of the application of the methodology are presented in Section 3. And finally, Section 4 is devoted to conclude the work

\section{METHODOLOGY}

The methodology implemented in this work is based on previous results obtained for building indoors and presented in (Díaz-Vilariño et al, 2018). Figure 1 represents the general workflow of the methodology.

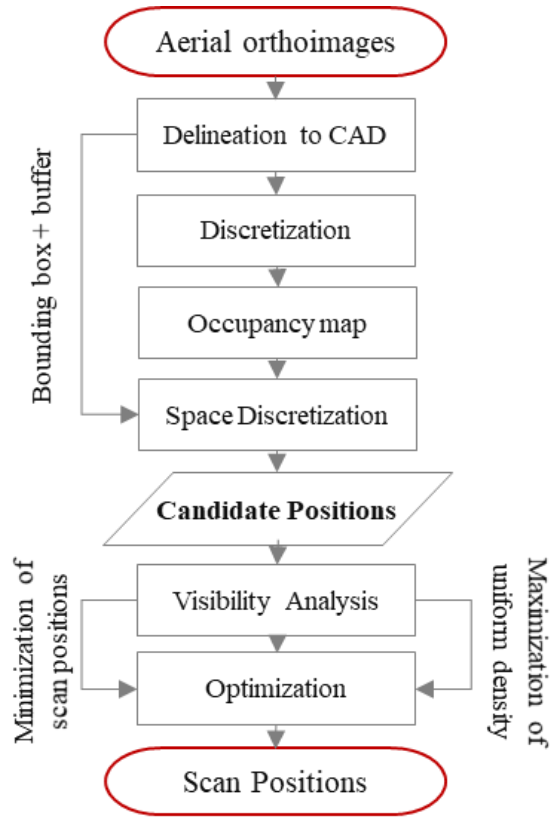

Figure 1. Workflow of the methodology.

\subsection{Delineation to CAD and Discretization to create Occupancy Maps}

Scan planning for big outdoor archaeological sites starts with the analysis of aerial orthoimages showing the extension and elements to acquire. The methodology is designed for the analysis of CAD - Computer Aided Design- files in which the elements of interest are represented in layers organized by element type. This organization of elements by semantics is used in future steps for planning the acquisition according to specific elements of interest. Therefore, the first step of this methodology is the manual delineation of orthoimages to CAD. In addition to the representation of archaeological elements such as walls, or columns, one layer is specifically devoted to represent the extension of the archaeological site, that is the exterior boundary of the navigable space.

Because geometric elements are represented in CAD by a small set of parameters, i.e. a line is represented by a starting point and an ending point, they need to be discretized into equally distributed points to facilitate further analysis, specially visibility analysis (Section 2.3.). Next a binary occupancy map is created to determine the space occupied by archaeological elements and the space that would be free to position the scan in order to capture the scene, what we further call 'navigable space'.

\subsection{Space Discretization}

Space discretization consists on distributing the navigable space into candidate scan positions, known as those theoretical places in which the scan can be placed. This step is critical in terms of processing time since visibility analysis (Section 2.3.) is highly influenced by the number of positions to analyse, and the effect is more pronounced as bigger is the area of study. The distribution of candidate positions can be carried out using different patterns such as grids, triangulations or tessellations. When the space is discretized in a grid, spatial resolution has to be defined. This parameter depends on the parameters of acquisition given by the sensor, such as laser range, and the point cloud density we want to obtain (Figure 2).

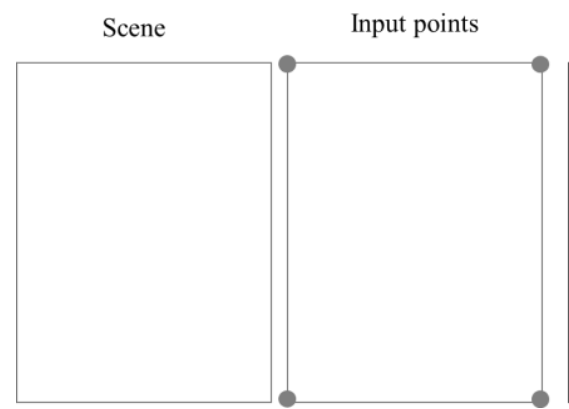

Discretization

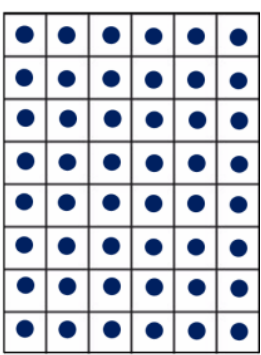

Figure 2. Schema of the discretization process when using a grid-based structure.

Complex floorplans usually require from high-density grids, but the analysis is very time consuming. Therefore, in this work a procedure based on the Delaunay triangulation is implemented. For this purpose, the vertices of lines defining elements of interest (i.e. lines and polylines depicting walls) and centres of circles such as in case of columns, are used as input points for the triangulation. When the line has a size higher than a certain threshold, $\mathrm{d}_{\max }$, the line is subdivided in order to generate points acting as input points in addition to vertices (Figure 3). In this way, the geometry of the elements of interest is taken into account for distributing the navigable space, but the number of candidate scan positions are much lower.

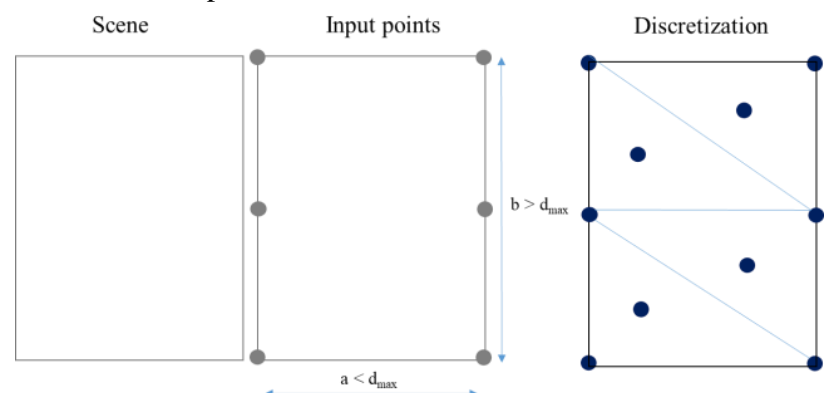

Figure 3. Schema of the discretization process when using a triangulation-based structure.

The limits of the navigable space are defined by the polyline representing the extension of the archaeological site and the archaeological elements themselves. According to the dimensions of the platform in which the laser scanner is going to be placed (i.e. a tripod a robot, etc.), a security distance is 
taken into account to discard those candidate positions too close to the limits of the navigable space and vertical elements.

\subsection{Visibility analysis and Optimization.}

Once candidate scan positions are determined, visibility analysis is performed to determine the theoretical area of the archaeological site that would be scanned. For this purpose, a ray-tracing algorithm is implemented (Figure 4). The algorithm is designed to perform the study within the neighbouring space (laser influence zone) in order to decrease computing time.

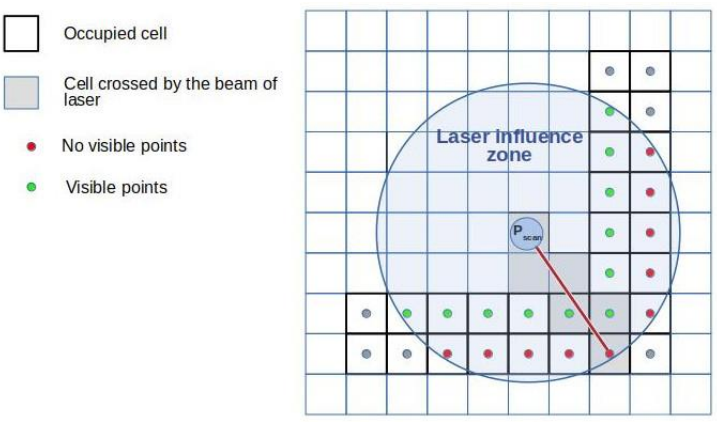

Figure 4. The principle of the ray-tracing algorithm (DíazVilariño et al, 2018).

Most of elements of the scene are visible for more than one candidate position. Consequently, scan positions have to be selected in a way that acquisition is optimal. In this work, optimization is performed to minimize the number of scan positions taking into account a certain coverage as stopping criteria. A back tracking algorithm is used to obtain the optimal scan positions.

\section{EXPERIMENTAL SECTION}

The methodology is tested in two real case studies. The first case study corresponds to the Roman Site "Aquis Querquennis" placed in the autonomous region of Galicia (Spain), and the second case study is the Roman City "Herdonia" in the province of Foggia (Italy).

\subsection{Case study 1. The Roman Site "Aquis Querquennis" (Bande, Spain)}

"Aquis Querquennis" was a military camp from Roman times, in Bande (Galicia, Spain), on the banks of the Limia river. Its occupation dates from the last quarter of the first to the middle of the second centuries. The encampment was likely built to monitor the construction of the roads communicating the cities of Bracara Augusta (Braga, Portugal) and Asturica Augusta (Astorga, Spain) (Puente et al, 2018).

As it can be observed in Figure 5, the settlement presents a classic layout with a rectangular shape and two main orthogonal paths and the area of study occupies 3 hectares.

The elements of interest are discretized into points using a separation distance $\left(d_{l}\right)$ of $100 \mathrm{~mm}$ for linear elements and a separation distance $d_{a}=d_{l} /$ radio for angular elements. Afterwards, the navigable space is distributed into candidate positions by using a triangulation-based procedure because of the high dimension of the case study ( 3 hectares). As it is shown in Table 1, triangulation enables a faster processing since less candidate positions are generated. For the generation of input points, $d_{\max }$ is considered $2.5 \mathrm{~m}$ meaning that lines or segments with higher dimension to $d_{\max }$ are subdivided to increase the density of vertices used as input points.

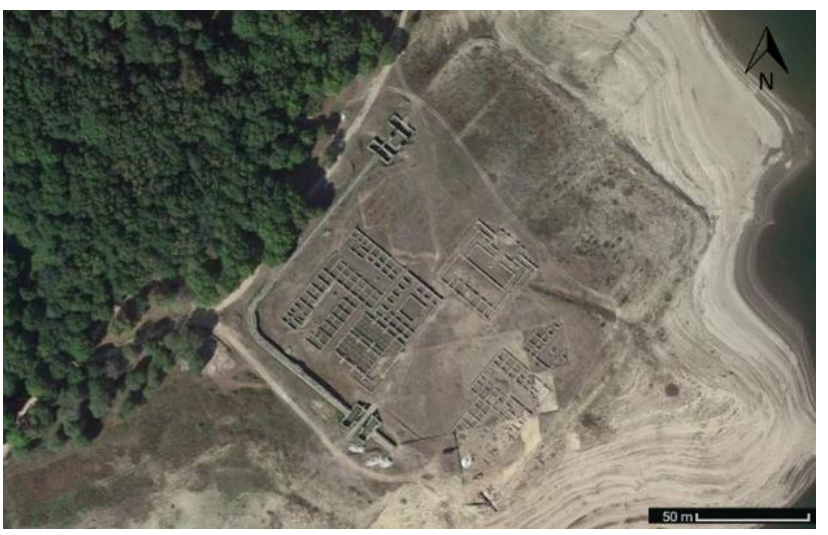

Figure 5. Situation of the Roman site 'Aquis Querquennis' in Bande (Spain) (Source: Google Maps).

From the ortoimage, the archaeological site has been delineated to $\mathrm{CAD}$ in hich walls and columns are organized in separated layers according to four zones depicted in Figure 6 with different colours.

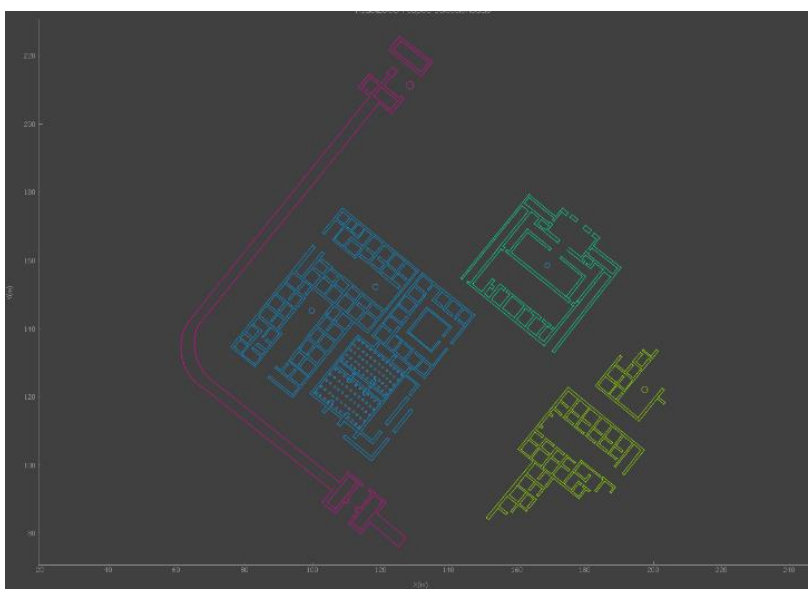

Figure 6. Distribution of 'Aquis Querquennis' in layers according to semantics.

Taking into account a security distance of $0.5 \mathrm{~m}, 1559$ candidate positions have been generated. Next, visibility is analysed for all candidate positions considering a laser range of $10 \mathrm{~m}$. Before visibility analysis, the scene is rotated with an angle of $51^{\circ}$ clockwise to orientate elements in a way that they are parallel to $x$ and $y$ axes as much as possible.

After optimization, 208 scan positions were obtained for an $90 \%$ of coverage considering the whole scene (Figure 7). From a practical point of view, if we consider 30 mins and $10.9 \times 10^{6}$ points per scan (assuming a configuration of Faro Focus x330), the complete acquisition of case study 1 will involve 104 hours and will result into $2267.2 \times 10^{6}$ points. This estimation highlights the importance of acquisition planning in archaeological sites. 


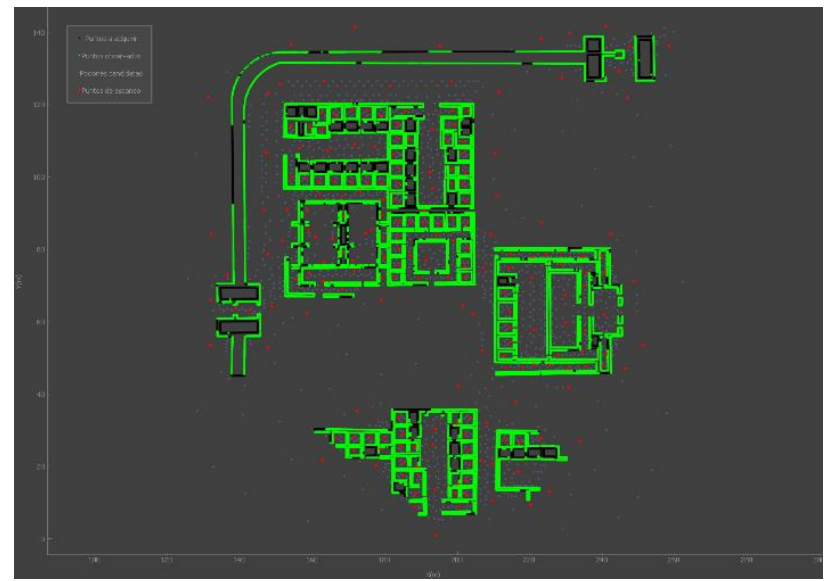

Figure 7. Candidate positions (in grey), scanning positions (in red) and scanned points (in green).

Since the elements of interest are distributed in layers according to semantics, the analysis can be directed to a specific zone. In order to show the differences between applying a grid-based or a triangulation-based discretization, Zone B is processed (Figure 8 and 9).

The results for applying a grid-based structure are shown in Figure 8. In Figure 8.a, all candidate positions are visualized in red. They were obtained by applying a $1.0 \mathrm{~m}$ spatial resolution to the navigable space and considering a security distance to building elements of $0.5 \mathrm{~m}$. After visibility analysis $(10 \mathrm{~m}$ of laser range) and optimization (90\% of coverage), 42 scan positions were obtained (Figure 8.b.). The theoretical area to be acquired by the selected scan positions is represented in green.

a)

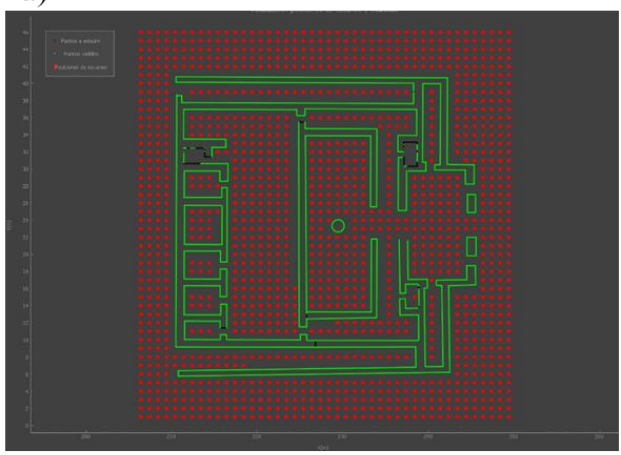

b)

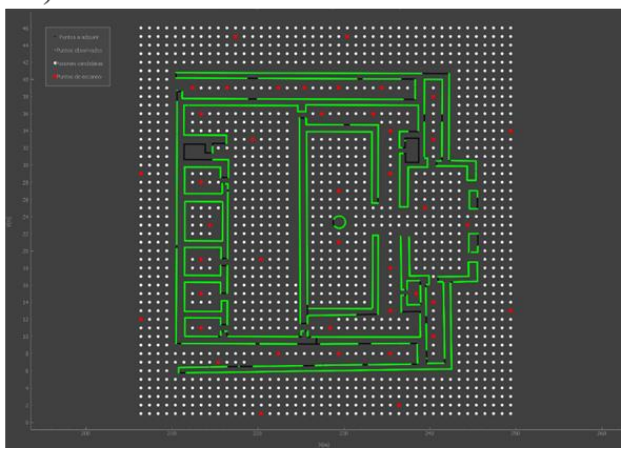

Figure 8. a) Candidate positions following a grid-based structure and b) scan positions after visibility analysis and optimization.
The results obtained for a triangulation-based discretization are shown in Figure 9. The input parameters in terms of security distance, laser range coverage are the same as in the grid-based test. However, in this case, the number of candidate positions is much lower and consequently, the processing time is fewer. The results show a number of scan positions higher to fulfil the coverage condition.

In Table 1, a summary of quantitative results is shown for the zone represented in Figures 8 and 9. It is prominent the higher number of candidates and processing time for a grid-based structure.

Table 1. Comparison of results for a grid-based and a triangulation based discretization for the zone represented in Figures 8 and 9.

\begin{tabular}{|l|c|c|}
\hline & $\begin{array}{c}\text { Grid-based } \\
\text { structure }\end{array}$ & $\begin{array}{c}\text { Triangulation- } \\
\text { based structure }\end{array}$ \\
\hline Candidate positions & 1392 & 239 \\
\hline Scan positions & 42 & 46 \\
\hline $\begin{array}{l}\text { Processing time for } \\
\text { candidate generation (s) }\end{array}$ & 63.4 & 3.34 \\
\hline $\begin{array}{l}\text { Processing time for } \\
\text { visibility analysis (s) }\end{array}$ & 198.92 & 26.87 \\
\hline
\end{tabular}

a)

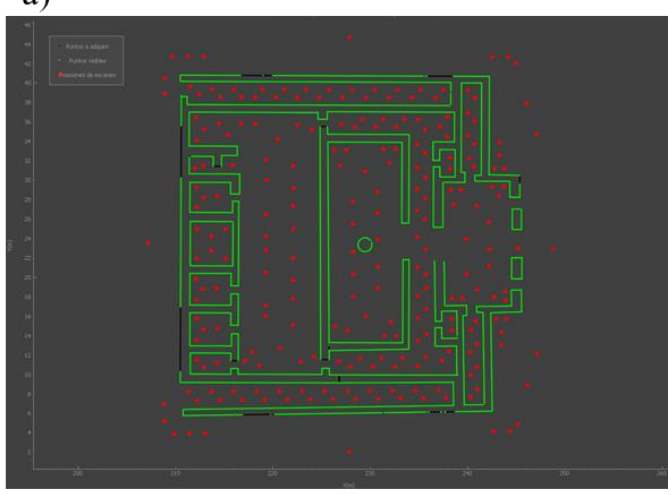

b)

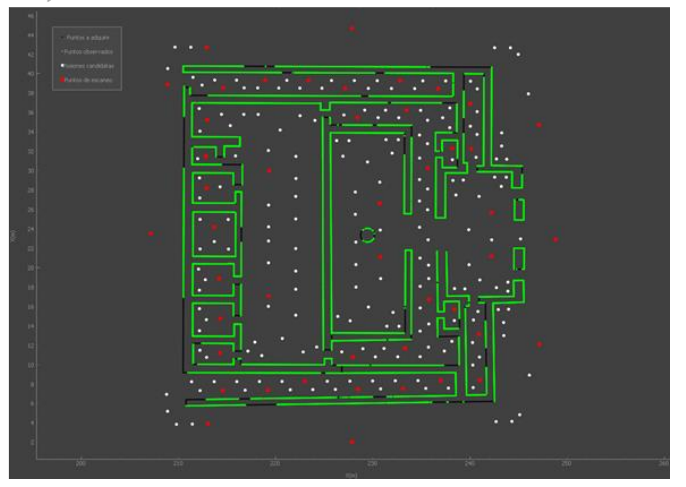

Figure 9. a) Candidate positions following a triangulation-based structure and b) scan positions after visibility analysis and optimization.

\subsection{Case study 2. The Roman City "Herdonia" (Foggia, Italia)}

"Herdonia" is a Roman city placed in the province of Foggia (Italy). Although the ruins of Herdonia were discovered after the Second World War, nowadays they are just partially excavated (Figure 10). The city reached its maximum 
development from the first to the fourth centuries due to the construction of the Via Traiana and Via Herdonitana. At that time, the city was an important transit and commercial centre.

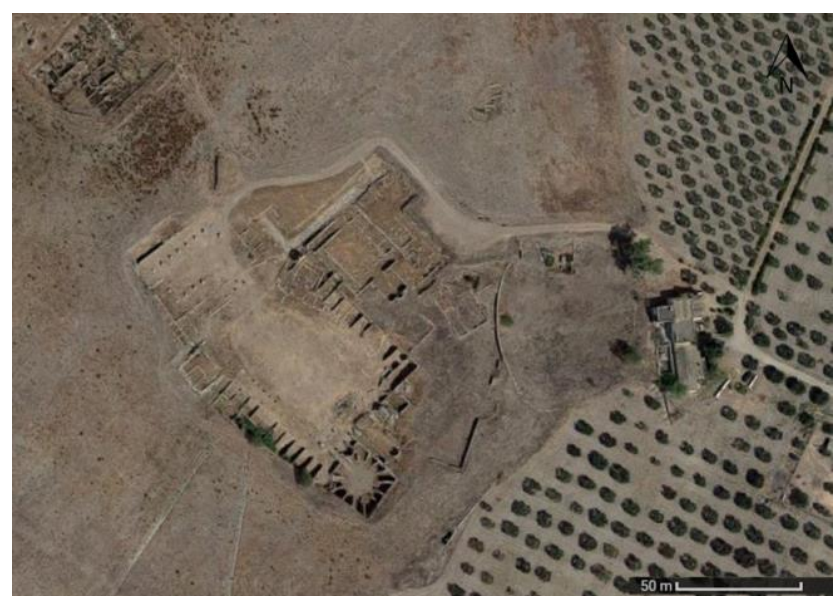

Figure 10. Situation of the Roman site 'Herdonia' in Foggia (Italy) (Source: Google Maps).

Next, as in the first case study, the Roman site 'Herdonia' has been delineated to a CAD file, and layers have been discretized into points for enabling the visibility analysis (Figure 11).

a)

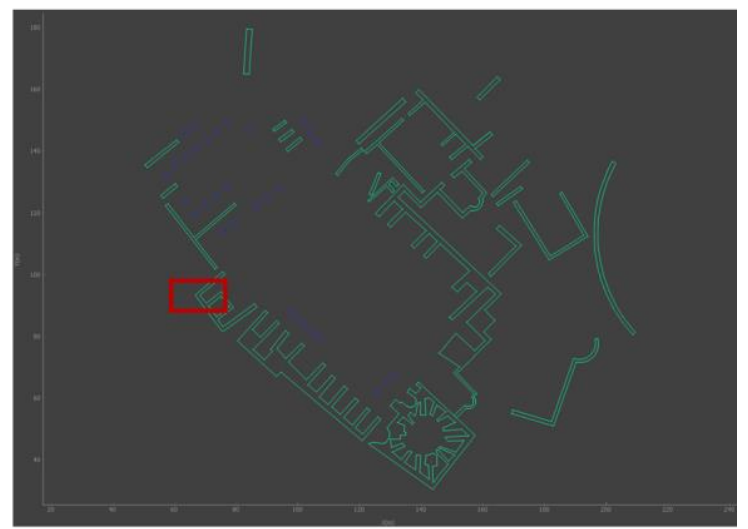

b)

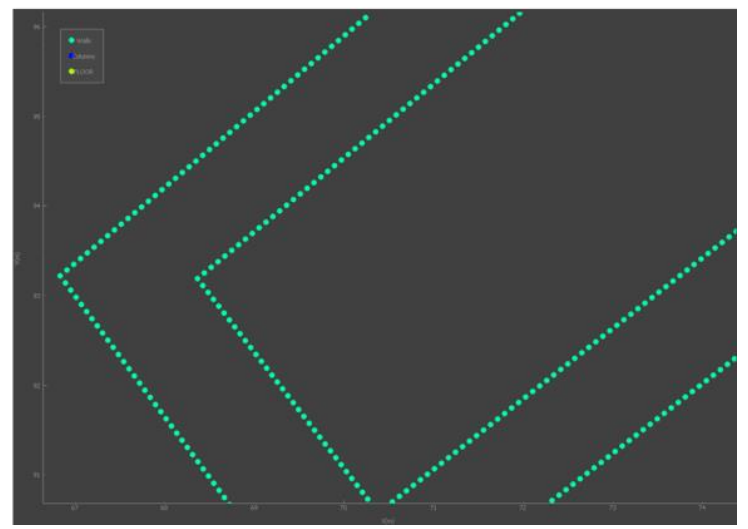

Figure 11. a) 'Herdonia' case study after delineation and discretization, b) a visualization of a small area to observe the discretization.

'Herdonia' case study was processed using the same parameters as in 'Aquis Querquennis' case study: element discretization of
$100 \mathrm{~mm}, 10 \mathrm{~m}$ of laser range, $0.5 \mathrm{~m}$ of security distance, and $90 \%$ of acquisition as stopping criteria. In this case, the scene was processed without rotation.

As a result, a total of 3025 candidates were generated, and from them, 128 positions were selected as final scan positions (Figure 12). Assuming an acquisition with Faro Focus x330 (488/2X), and estimating 30 mins and $10.9 \times 10^{6}$ points per scan, the complete acquisition will involve 64 hours of work, and $1395.2 \times 10^{6}$ points.

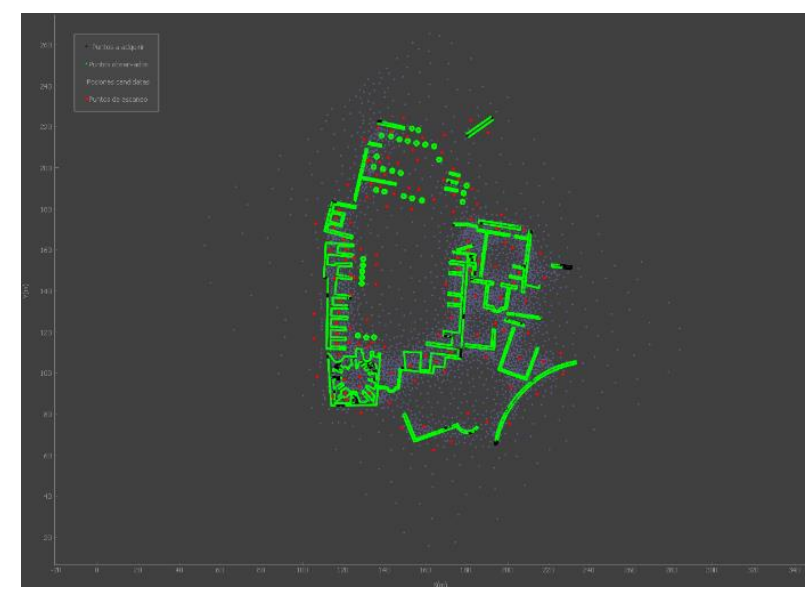

Figure 12. Candidate positions (in grey), scanning positions (in red) and scanned points (in green) for the case study.

\section{CONCLUSIONS}

In this paper, an automatic methodology to optimize the number and position of scans for the surveying large archaeological sites is proposed. The methodology aims to optimize the number of scans in an order to obtain a point cloud of high quality in terms of data completeness.

Although the problem of scan planning has been mostly considered for indoors, the planning of an acquisition for archaeological sites is of special interest because of the big area they cover and because of the complexity of archaeological remains.

The methodology is tested in two real case studies: 'Aquis querquennis' in Galicia (Spain) and 'Herdonia' in Foggia (Italia). Results depend on several parameters such as laser range and security distance, that can be configurable depending on the sensor and platform considered for the planning. In addition, two different configurations for discretizing the navigable space into candidate positions are evaluated. From the results, we can conclude that a triangulation-based distribution is more suitable for large areas of study since the number of candidate scan positions is lower, and consequently, the processing time is faster, especially for visibility analysis.

Since the objective of the implementation is to optimize the acquisition by minimizing the number of scan positions, and consequently, minimizing the scanning time and the amount of data, overlapping between scan positions is not ensured. In this context, manual registration could be difficult when the real position and orientation of scans is not known. In case of using a robotic platform to implement and Stop \& Go acquisition, and in which the navigation is performed by using SLAM, the position and orientation given by the robotic platform would enable a rough registration that could be refined next (DíazVilariño, et al, 2018).

In addition to minimize the number of scans, for future work, optimization will consider the maximization of the uniformity 
of point cloud density. Combination of terrestrial and aerial point cloud acquisitions will also be explored for large archaeological sites. And efforts in this line will be directed to develop automatic methodologies to process and extract useful information from the data.

\section{ACKNOWLEDGEMENTS}

Authors would like to thank to the Xunta de Galicia given through human resources grant (ED481B 2016/079-0), the Universidade de Vigo for the financial support (00VI $131 \mathrm{H}$ 641.02), competitive reference group (ED431C 2016-038), Ministerio de Economia, Industria y Competitividad -Gobierno de España- (TIN2016-77158-C4-2-R, RTC-2016-5257-7), and COST Action CA15201. The statements made herein are solely the responsibility of the authors.

\section{REFERENCES}

Ahn, J., and Wohn, K., 2016. Interactive scan planning for heritage recording. Multimedia Tools and Applications, 75(7), 3655-3675.

Balletti, C., Guerra, F., Scocca, V., Gottardi, C., 2015. 3D integrated methodologies for the documentation and the virtual reconstruction of an archaeological site. The International Archives of Photogrammetry, Remote Sensing and Spatial Information Sciences, 40(5), 215.

Barbieri, L., Bruno, F., Muzzupappa, M., 2018. User-centered design of a virtual reality exhibit for archaeological museums. International Journal on Interactive Design and Manufacturing (IJIDeM), 12(2), 561-571.

Barsanti, S. G., Remondino, F., Visintini, D., 2012. Photogrammetry and Laser Scanning for archaeological site 3D modeling-Some critical issues. In Proc. of the 2nd Workshop on'The New Technologies for Aquileia', V. Roberto, L. Fozzati.

Blaer, P. S., and Allen, P. K., 2006. View planning for automated site modeling. In Proceedings 2006 IEEE International Conference on Robotics and Automation, 2006. ICRA 2006. (pp. 2621-2626). IEEE.

Boehler, W., Vicent, M. B., Marbs, A., 2003. Investigating laser scanner accuracy. The International Archives of Photogrammetry, Remote Sensing and Spatial Information Sciences, 34(Part 5), 696-701.

Díaz-Vilariño, L., Frías, E., Balado, J., and González-Jorge, H.: Scan planning and route optimization for control of execution of as-designed BIM, The International Archives of Photogrammetry, Remote Sensing and Spatial Information Sciences, XLII-4, 143-148, https://doi.org/10.5194/isprsarchives-XLII-4-143-2018, 2018.

Doneus, M., and Neubauer, W., 2005. Laser scanners for 3D documentation of stratigraphic excavations. Recording, modeling and visualization of cultural heritage, 193-203.

Entwistle, J. A., McCaffrey, K. J., Abrahams, P. W., 2009. Three-dimensional (3D) visualisation: the application of terrestrial laser scanning in the investigation of historical Scottish farming townships. Journal of Archaeological Science, 36(3), 860-866.
Forte, M., Dell'Unto, N., Issavi, J., Onsurez, L., and Lercari, N., 2012. 3D archaeology at Çatalhöyük. International Journal of Heritage in the Digital Era, 1(3), 351-378.

Fujimoto, K., Beniyama, F., Moriya, T., Nakayama, Y., 2008. Reconstruction of 3D indoor model by scalable sensing using mobile robot. In Three-Dimensional Image Capture and Applications 2008 (Vol. 6805, p. 68050I). International Society for Optics and Photonics.

Kincey, M., Gerrard, C., Warburton, J., 2017. Quantifying erosion of 'at risk' archaeological sites using repeat terrestrial laser scanning. Journal of Archaeological Science: Reports, 12, 405-424.

Low, K. L. (2006). View planning for range acquisition of indoor environments (pp. 0985-0985). University of North Carolina at Chapel Hill.

Nagatani, K., Matsuzawa, T., Yoshida, K., 2010. Scan-point planning and 3-d map building for a 3-d laser range scanner in an outdoor environment. In Field and service robotics (pp. 207217). Springer, Berlin, Heidelberg.

Previtali, M., Stanga, C., Molnar, T., Van Meerbeek, L., \& Barazzetti, L. (2018). An integrated approach for threat assessment and damage identification on built heritage in climate-sensitive territories: the Albenga case study (San Clemente church). Applied Geomatics, 10(4), 485-499.

Puente, I., Solla, M., Lagüela, S., Sanjurjo-Pinto, J. Reconstructing the Roman Site 'Aquis Querquernnnis' (Bande, Spain) from GPR, T-LiDAR and IRT Data Fusion. Remote Sensing, 10, 379, 1-16, 2018. 